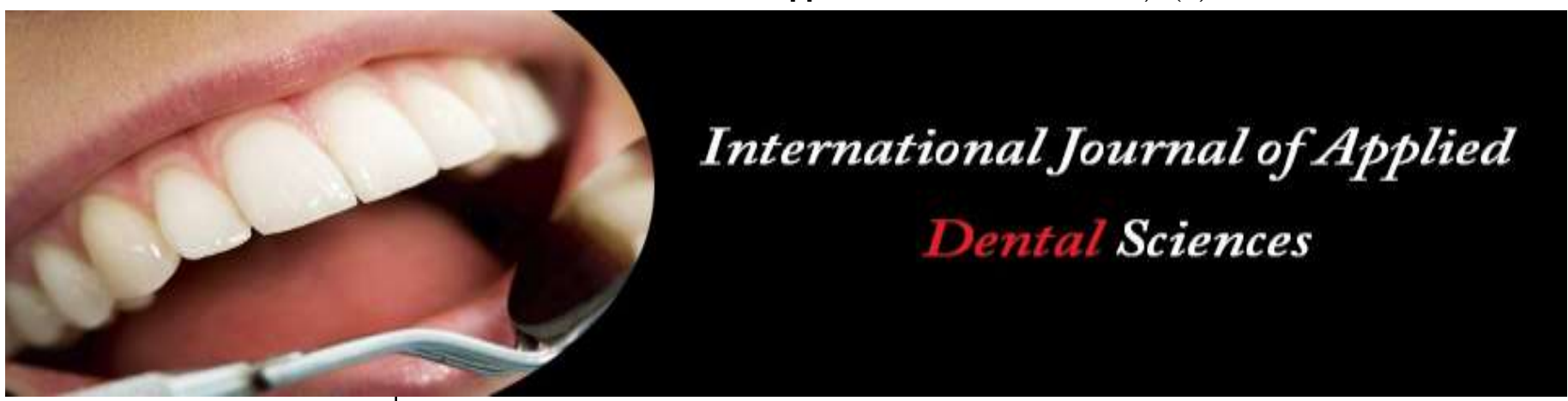

ISSN Print: 2394-7489

ISSN Online: 2394-7497

IJADS 2020; 6(4): 376-383

(C) 2020 IJADS

www.oraljournal.com

Received: 03-09-2020

Accepted: 15-10-2020

Dr. Sunkara VV Manikanta

Swamy

Postgraduate Student,

Government Dental College and

Hospital, Afzalgunj, Hyderabad,

Telangana, India

Dr. Chandulal Jadav

Professor and Head, Government

Dental College and Hospital,

Afzalgunj, Hyderabad,

Telangana, India

Dr. Narasimha Lakshmi M Assistant Professor, Government

Dental College and Hospital,

Afzalgunj, Hyderabad,

Telangana, India

Dr. Gouthami Mothe

Postgraduate Student,

Government Dental College and

Hospital, Afzalgunj, Hyderabad,

Telangana, India

Dr. Benaaz M Asudaria

Postgraduate Student,

Government Dental College and

Hospital, Afzalgunj, Hyderabad,

Telangana, India
Corresponding Author:

Dr. Sunkara VV Manikanta

Swamy

Postgraduate Student,

Government Dental College and Hospital, Afzalgunj, Hyderabad,

Telangana, India

\section{Comparision of the attractiveness by virtual alteration of the male and female profile of class II division 1 malocclusion: A perception study}

\author{
Dr. Sunkara VV Manikanta Swamy, Dr. Chandulal Jadav, Dr. Narasimha \\ Lakshmi M, Dr. Gouthami Mothe and Dr. Benaaz M Asudaria
}

DOI: https://doi.org/10.22271/oral.2020.v6.i4f.1091

\section{Abstract}

This study is done to obtain the perception of lay people and dentists for virtually altered profile image of male and female class II division 1 patient simulating the treatment outcome. The digital profile images of skeletal class II division 1 malocclusion male and female patients produced by virtual alteration on dolphin imaging software (version 11.4) and printed on to the booklet, dentists and laypeople were asked to rate the set of profiles on Visual Analog scale of 1-10. The groups laypeople, dentists assigned highest Rank scores for increase in chin neck length of $57 \mathrm{~mm}$ (Profile G) and considered most attractive and least scores for unaltered base image (Profile D) for male profile and for female profiles laypeople assigned highest score for increase in Nasolabial angle 121 degrees (Profile B), dentists assigned highest score for increase in Chin neck length $54 \mathrm{~mm}$ (Profile F).

Keywords: Perception, virtual alteration, laypeople, nasolabial angle

\section{Introduction}

The consciousness of facial beauty and attractiveness is more in young and adult individuals of current generations. The attractive people are more preferred in hiring and promotion, they are smarter and socially skilled. The procedures that improve the profile of skeletal class II division 1 malocclusion by reducing the convexity includes camouflage to alter the acute Nasolabial angle and Mandibular advancement protocols like functional advancements and Orthognathic surgeries based on the residual growth.

The Angle has used the terms balance, harmony, beauty and ugliness, the concept of beauty and orthodontic treatment has changed from harmony and balance in the past to the present concept of acceptable appearance of the soft tissue. ${ }^{[1]}$

The perception of esthetics and beauty differs between dentists and lay persons and the patient undergoing the orthognathic surgery have a thorough knowledge about treatment outcome and results, but the profile change is more easily perceived than a frontal change and the patient does not view himself in the Profile view and has little appreciation of the treatment outcomes. ${ }^{[2]}$ The Throat length or cervicomental length is valuable in assessing the mandibular position in class II skeletal and dental malocclusions. In case of mandible with short cervicomental length the clinician must be careful about the surgical procedures that reduce the prominence of chin or pogonion. It is better to have the assessment and rating of the laypeople as these are the one who will judge the attractiveness and the facial beauty in the society.

Hence, this study aims to obtain the perception of laypeople on the profile images of skeletal class II division 1 patient that were generated by altering the nasolabial angles and chin neck lengths. This study also evaluates the comparision of the perception between the laypeople and dentists on these altered digital profile images.

\section{Materials and Methods}

A perception study was conducted by altering the digital profile photo of male and female skeletal class II division 1 patient on dolphin software. 


\subsection{Requirements for this study}

1. Digital Profile image and lateral cephalogram of male and female individual with untreated skeletal class II division 1 malocclusion.

2. Dolphin imaging software and management solutions (version 11.4).

3. Adobe photoshop software (version creative suite 6).

4. A sample of 160 laypeople (who passed atleast high school) in age group between 18-30 years, 50 dentists to assess the profile images.(Figure 1)

5. Printed booklets depicting virtually altered profile images.

\subsection{Methodology}

\subsubsection{Virtual Alteration of Profile Images}

The patients were informed about the study and informed written consent was taken. A profile image and a lateral cephalogram of an untreated skeletal class II division 1 malocclusion were scanned and imported in to software (Dolphin Imaging and Management Solutions - version 11.4) where the images were linked to each other to standardize the profile image with the given magnification of the lateral cephalogram. (Figure 2)

The profile picture of the subject was first altered with Photoshop software (Adobe photoshop CS6) to emphasize the Mandibular retrusion. For the chin-neck length, the norm given by Lehman et al. ${ }^{[3]}$ is used $57 \pm 6 \mathrm{~mm}$ minus 2 standard deviations, resulting in $45 \mathrm{~mm}$, was used as the starting point for the alterations of this variable. The same was carried out for the Nasolabial angle by using norms given by Sinno et al. ${ }^{[4]}$ for females to $104.9 \pm 4^{0}$ and for males a norm of $97.0 \pm 6.3^{0}$.

The starting point for all alterations with a chin-neck length of $45 \mathrm{~mm}$ and a Nasolabial angle of $104.9^{\circ}$ for females and for males $97^{\circ}$ was used. This was the profile with the most pronounced Class II Division 1 features, displaying the greatest sagittal interlabial step.

The profile image is digitally altered by dolphin software, increasing chin neck length simulating the treatment outcome of Mandibular advancement surgery, (subsequently by +1.0 ,
$1.5,2.0 \mathrm{SD}$ ) resulting in chin neck lengths of $51 \mathrm{~mm}, 54 \mathrm{~mm}$, $57 \mathrm{~mm}$ were noted as Profile E, F, G respectively. The same was carried out for the Nasolabial angle and altered to create 3 additional profile types by increasing the angle (by +2.0 , 4.0, 6.0 SD) from the norm resulting in $113^{0}, 121^{0}, 129^{\circ}$ for females and $110^{\circ}, 122^{\circ}, 135^{\circ}$ for males noted as profile A, B, $\mathrm{C}$ respectively.

\subsubsection{Perception and Rating by Lay people}

These altered 6 profile images along with base line image and questionnaire (Figure 3) on age, sex, nationality, educational level of observer were printed in to a booklet containing male perception form (Figure 4) and female perception form (Figure 5) and this was given to 160 lay people and 50 dentists and were asked to judge and give overall rank to the 7 set of profiles ranging from 7 for most attractive to 1 for least attractive profile. The participants includes 160 lay people of $18-30$ years of age.

The participants were also asked to score the individual profiles whether acceptable or unacceptable on a Visual Analog Scale (VAS) numbered from 1 to 10 , described non attractive on left side of this scale and attractive on right side.

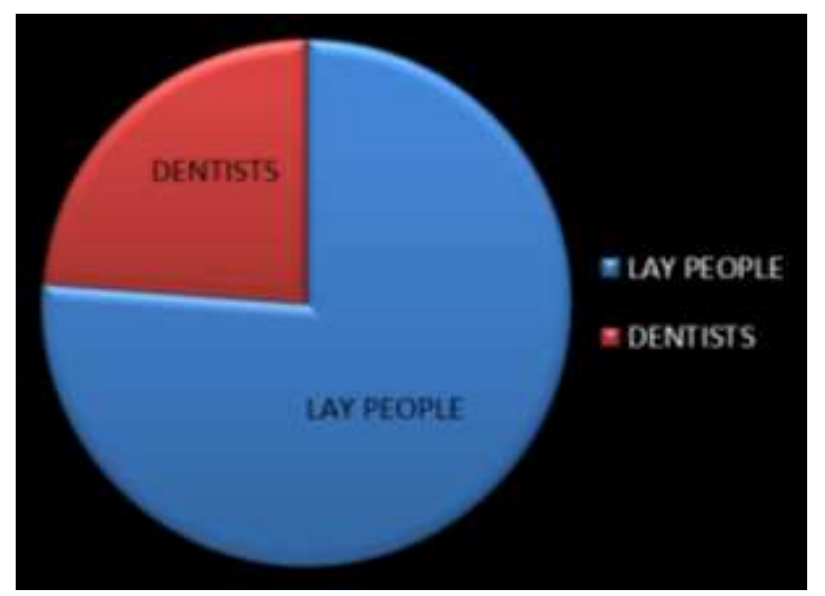

Fig. 1: Distribution of the raters
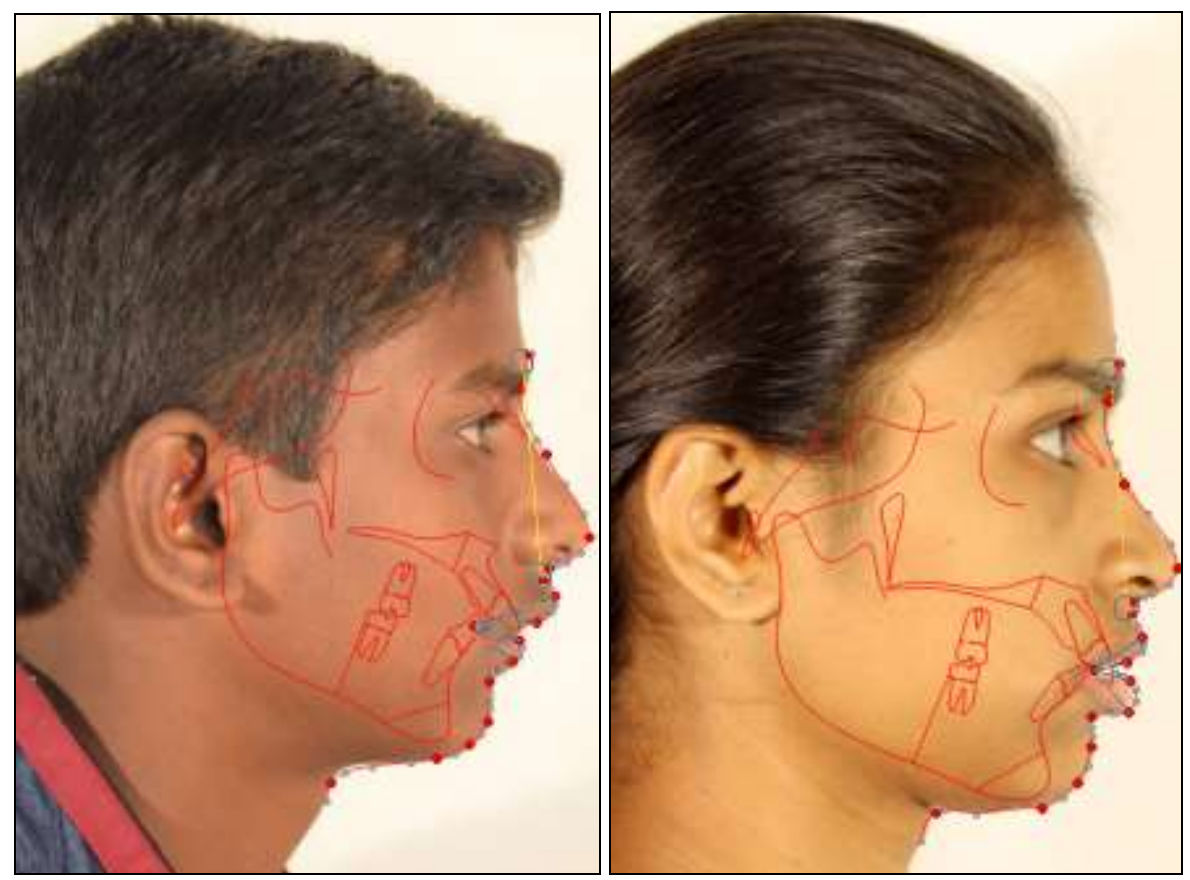

Fig 2: superimposed digital profile photograph of male and female on dolphin software 




Fig. 3: Questionnaire for perception assessment

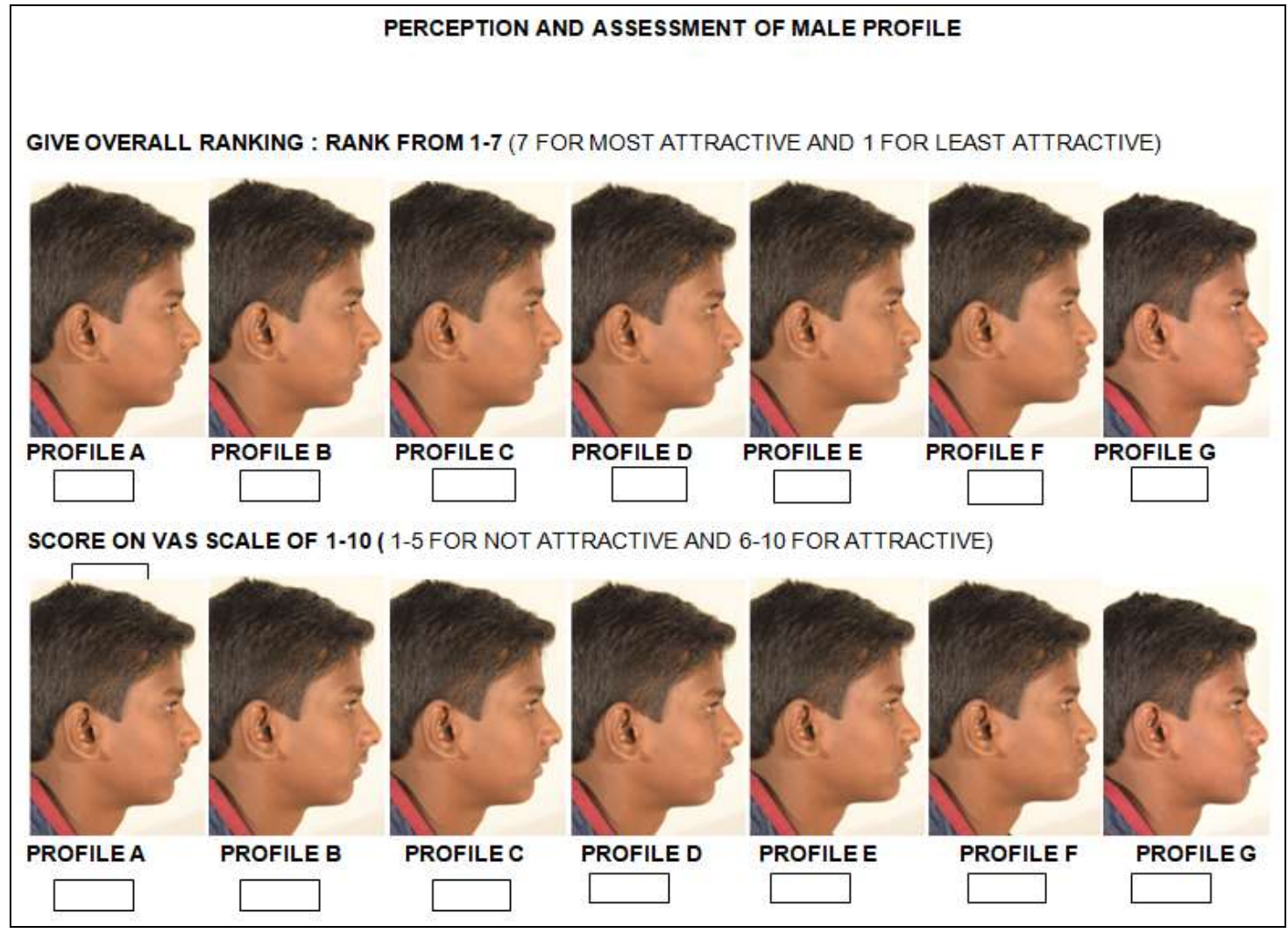

Fig 4: Perception assessment form for male profile 


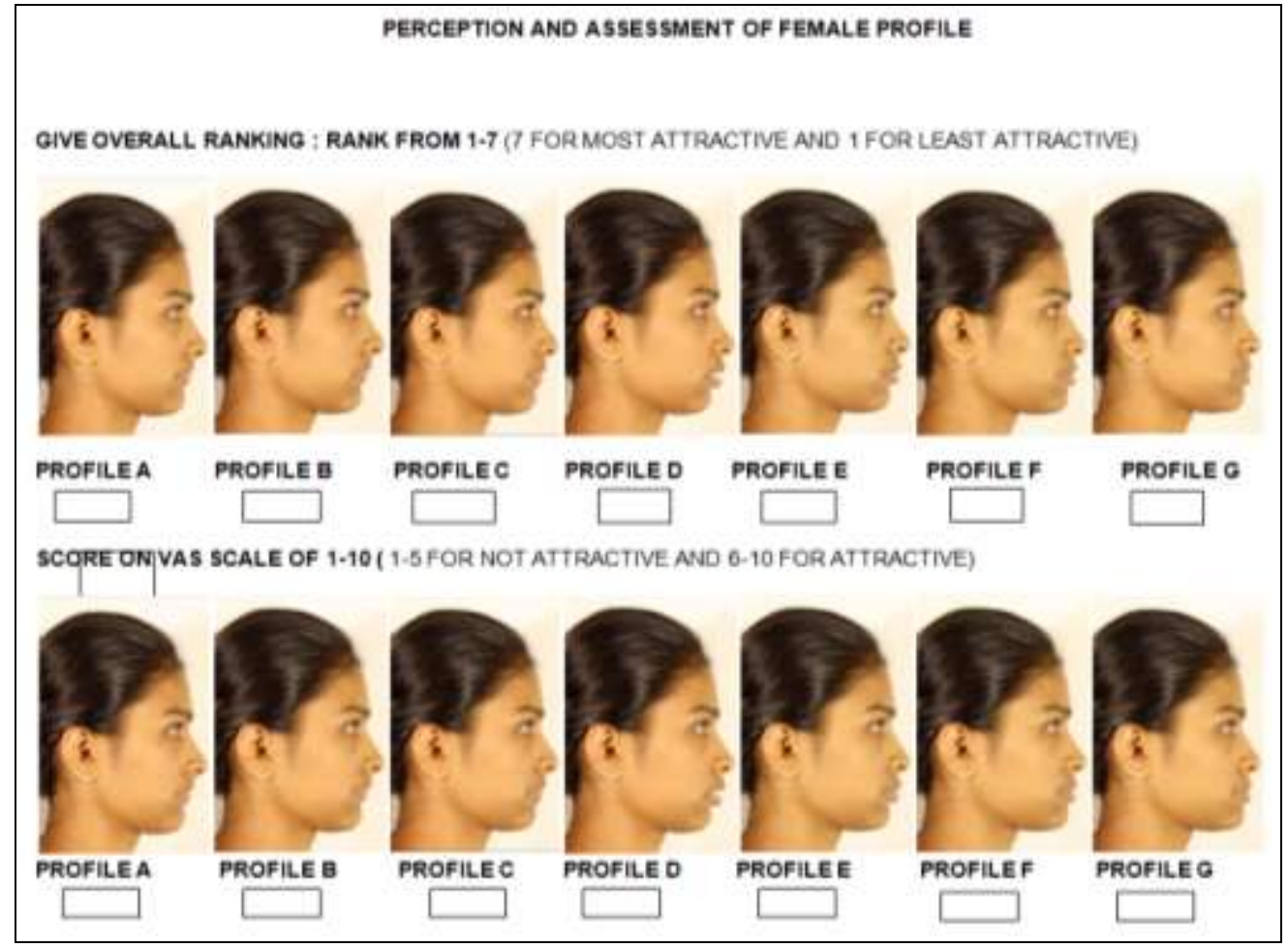

Fig 5: perception assessment form for female profile

\section{Results}

The mean scores are obtained for the rankings and compared using $t$ test

Table 1: Comparison of mean rank scores between laypeople and dentists for male profile by ' $t$ ' test

\begin{tabular}{|c|c|c|c|c|c|}
\hline Profile & Groups & $\mathbf{N}$ & Mean & SD ( $( \pm)$ & P value \\
\hline Profile A & $\begin{array}{l}\text { Laypeople } \\
\text { Dentists }\end{array}$ & $\begin{array}{c}160 \\
50\end{array}$ & $\begin{array}{l}3.21 \\
2.24\end{array}$ & $\begin{array}{l} \pm 1.930 \\
\pm 1.170\end{array}$ & 0.001 \\
\hline Profile B & $\begin{array}{l}\text { Laypeople } \\
\text { Dentists }\end{array}$ & $\begin{array}{c}160 \\
50\end{array}$ & $\begin{array}{l}4.08 \\
3.22\end{array}$ & $\begin{array}{l} \pm 1.596 \\
\pm 1.112\end{array}$ & 0.001 \\
\hline Profile C & $\begin{array}{l}\text { Laypeople } \\
\text { Dentists }\end{array}$ & $\begin{array}{c}160 \\
50\end{array}$ & $\begin{array}{l}3.96 \\
3.74\end{array}$ & $\begin{array}{l} \pm 1.678 \\
\pm 1.084\end{array}$ & 0.379 \\
\hline Profile D & $\begin{array}{l}\text { Laypeople } \\
\text { Dentists }\end{array}$ & $\begin{array}{c}160 \\
50\end{array}$ & $\begin{array}{l}2.33 \\
1.80\end{array}$ & $\begin{array}{l} \pm 1.452 \\
\pm 1.414\end{array}$ & 0.026 \\
\hline Profile E & $\begin{array}{l}\text { Laypeople } \\
\text { Dentists }\end{array}$ & $\begin{array}{c}160 \\
50\end{array}$ & $\begin{array}{l}4.56 \\
5.36\end{array}$ & $\begin{array}{l} \pm 1.666 \\
\pm 1.274\end{array}$ & 0.002 \\
\hline Profile F & $\begin{array}{l}\text { Laypeople } \\
\text { Dentists }\end{array}$ & $\begin{array}{c}160 \\
50\end{array}$ & $\begin{array}{l}4.03 \\
5.28\end{array}$ & $\begin{array}{l} \pm 1.928 \\
\pm 1.371\end{array}$ & 0.001 \\
\hline Profile G & $\begin{array}{c}\text { Laypeople } \\
\text { Dentists }\end{array}$ & $\begin{array}{c}160 \\
50\end{array}$ & $\begin{array}{l}5.88 \\
6.32 \\
\end{array}$ & $\begin{array}{l} \pm 1.806 \\
\pm 1.168 \\
\end{array}$ & 0.108 \\
\hline
\end{tabular}

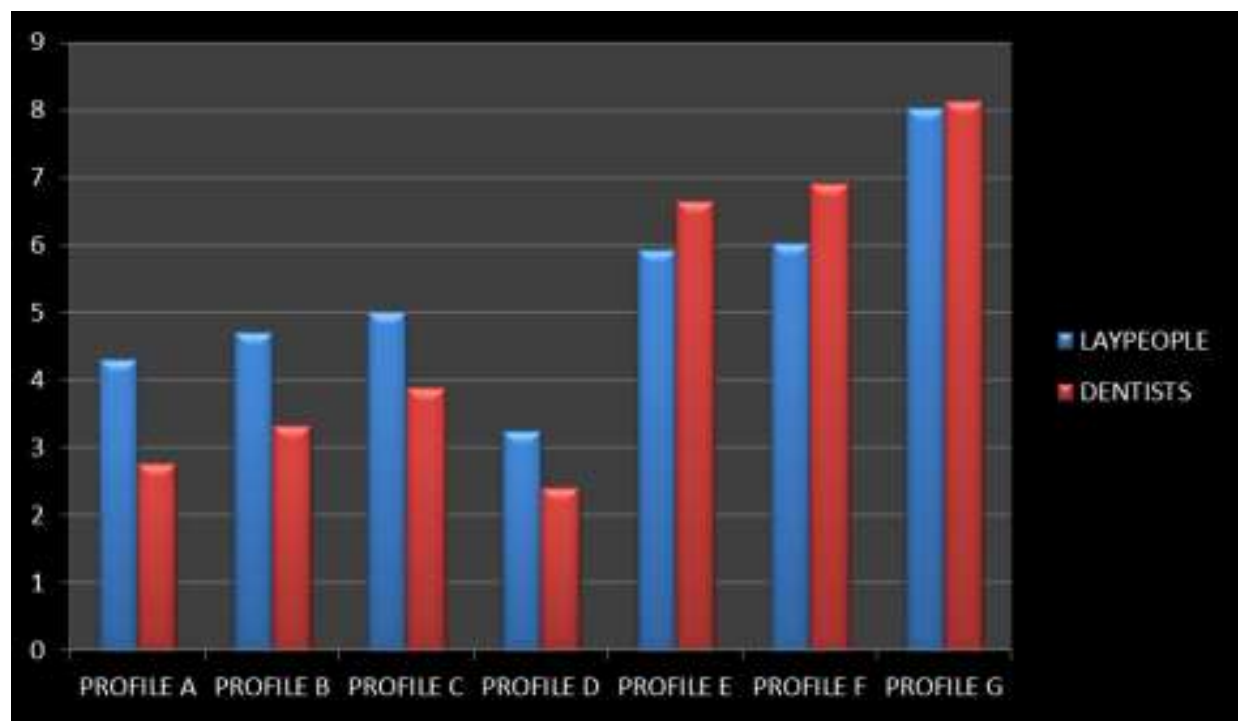

Fig 6: Analysis of rank mean scores for male profile 
Table 2: Analysis of VAS mean scores given by laypeople, dentists for male profile

\begin{tabular}{|c|c|c|}
\hline \multirow{2}{*}{ Profile } & \multicolumn{2}{|c|}{ Mean VAS score } \\
\cline { 2 - 3 } & Laypeople & Dentists \\
\hline Profile A & $4.31(2)$ & $2.76(2)$ \\
\hline Profile B & $4.70(3)$ & $3.32(3)$ \\
\hline Profile C & $5.01(4)$ & $3.88(4)$ \\
\hline Profile D & $3.24(1)$ & $2.40(1)$ \\
\hline Profile E & $5.93(5)$ & $6.66(5)$ \\
\hline Profile F & $6.03(6)$ & $6.92(6)$ \\
\hline Profile G & $8.04(7)$ & $8.14(7)$ \\
\hline
\end{tabular}

In parentheses, the final ranking order is shown, with 1 the least attractive and 7 the most attractive.

The above table represents the difference in final mean VAS scores between laypeople, dentists. All groups assigned highest score for Profile $G$ and considered it as most attractive and least score for profile D and considered it as unattractive.

\section{Perception of laypeople}

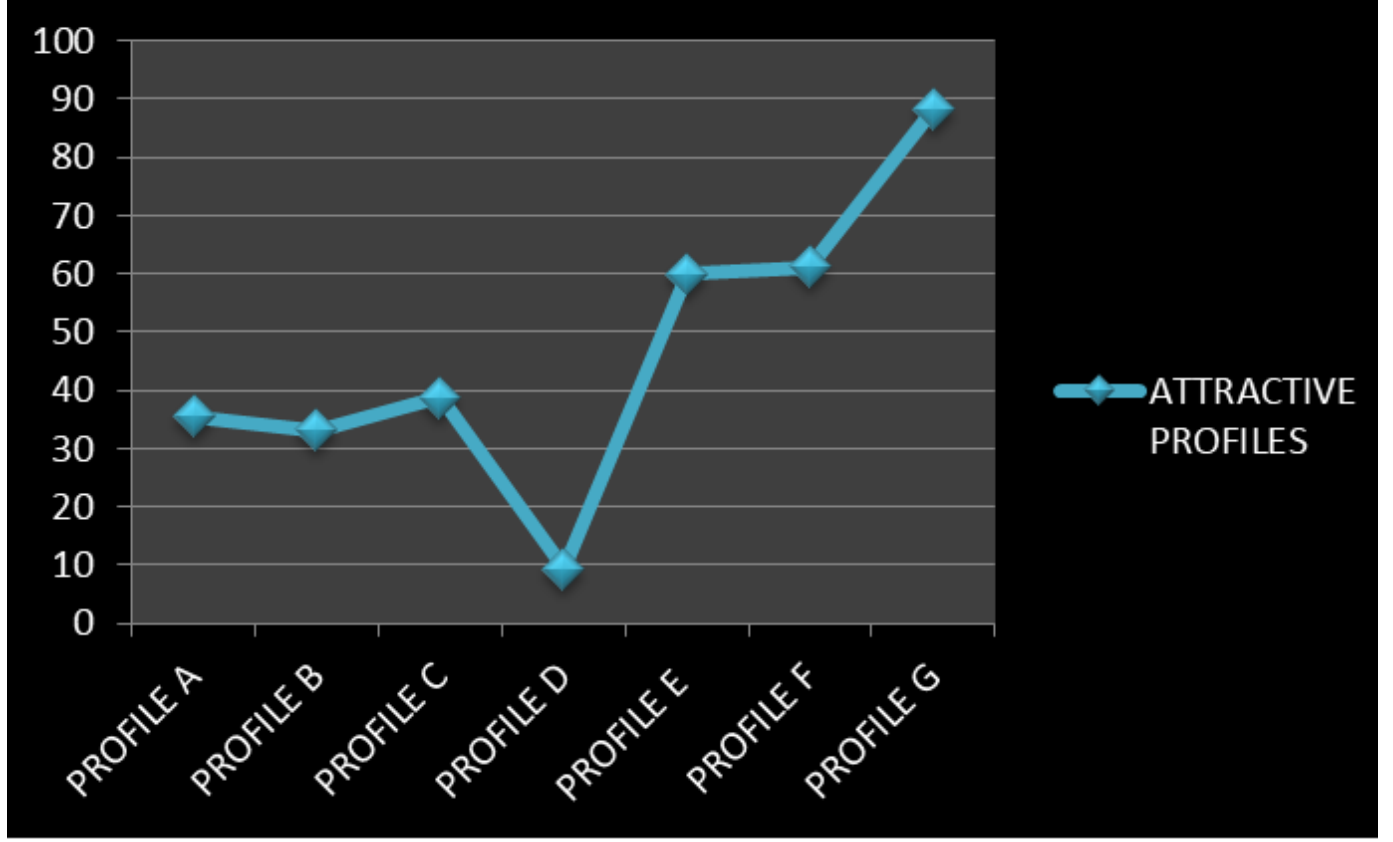

\section{Perception of dentists}

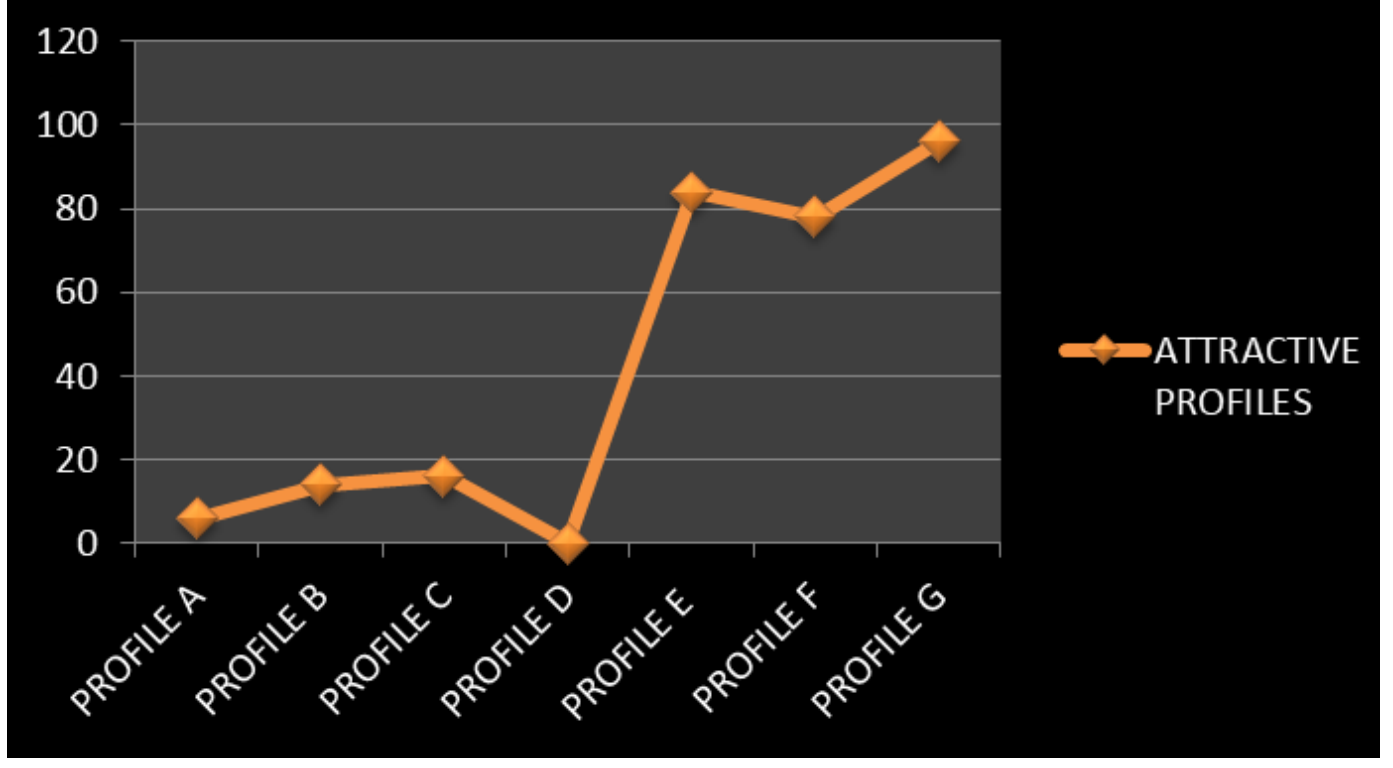

Fig 7: Percentage of attractiveness by laypeople and dentists for male profile 
Table 3: Comparison of mean rank scores between laypeople and dentists for female profile by ' $t$ ' test

\begin{tabular}{|c|c|c|c|c|c|}
\hline Profile & Groups & $\mathbf{N}$ & Mean & SD ( $( \pm)$ & P value \\
\hline Profile A & $\begin{array}{c}\text { Laypeople } \\
\text { Dentists }\end{array}$ & $\begin{array}{c}160 \\
50\end{array}$ & $\begin{array}{l}4.11 \\
2.92\end{array}$ & $\begin{array}{l} \pm 2.239 \\
\pm 1.724\end{array}$ & 0.001 \\
\hline Profile B & $\begin{array}{c}\text { Laypeople } \\
\text { Dentists }\end{array}$ & $\begin{array}{c}160 \\
50\end{array}$ & $\begin{array}{l}4.47 \\
3.72\end{array}$ & $\begin{array}{l} \pm 1.686 \\
\pm 1.852\end{array}$ & 0.008 \\
\hline Profile C & $\begin{array}{c}\text { Laypeople } \\
\text { Dentists }\end{array}$ & $\begin{array}{c}160 \\
50\end{array}$ & $\begin{array}{l}4.14 \\
4.42\end{array}$ & $\begin{array}{l} \pm 1.503 \\
\pm 1.513\end{array}$ & 0.248 \\
\hline Profile D & $\begin{array}{c}\text { Laypeople } \\
\text { Dentists }\end{array}$ & $\begin{array}{c}160 \\
50\end{array}$ & $\begin{array}{l}1.77 \\
1.76\end{array}$ & $\begin{array}{l} \pm 1.393 \\
\pm 1.135\end{array}$ & 0.968 \\
\hline Profile E & $\begin{array}{c}\text { Laypeople } \\
\text { Dentists }\end{array}$ & $\begin{array}{c}160 \\
50\end{array}$ & $\begin{array}{l}4.44 \\
4.68\end{array}$ & $\begin{array}{l} \pm 1.693 \\
\pm 1.544\end{array}$ & 0.380 \\
\hline Profile F & $\begin{array}{c}\text { Laypeople } \\
\text { Dentists }\end{array}$ & $\begin{array}{c}160 \\
50\end{array}$ & $\begin{array}{l}4.48 \\
5.40\end{array}$ & $\begin{array}{l} \pm 1.723 \\
\pm 1.616\end{array}$ & 0.001 \\
\hline Profile G & $\begin{array}{c}\text { Laypeople } \\
\text { Dentists }\end{array}$ & $\begin{array}{c}160 \\
50 \\
\end{array}$ & $\begin{array}{l}4.54 \\
5.60 \\
\end{array}$ & $\begin{array}{l} \pm 2.071 \\
\pm 1.823 \\
\end{array}$ & 0.111 \\
\hline
\end{tabular}

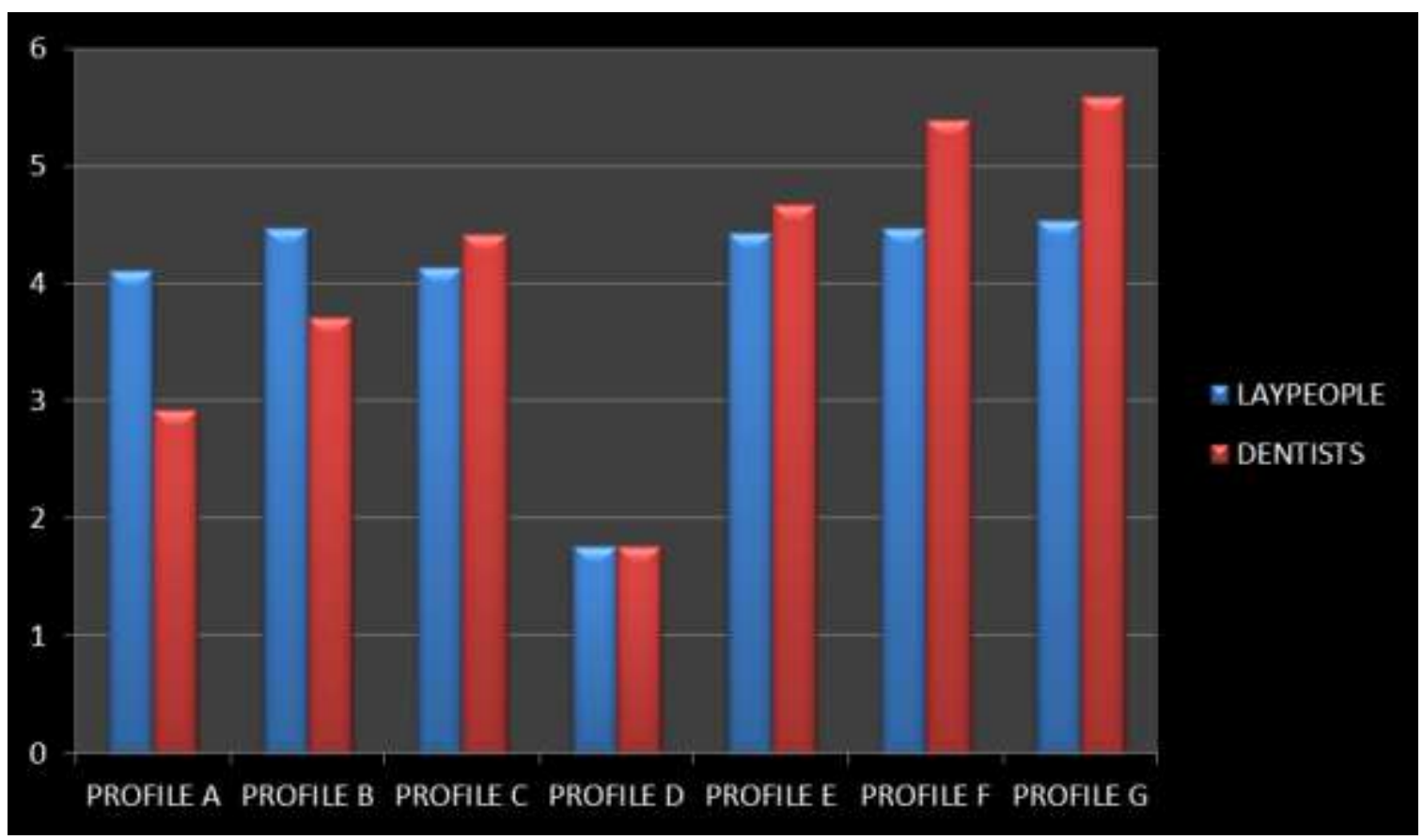

Fig 8: Comparision of mean rank scores between laypeople and dentists for female profile

Table 4: Analysis of VAS scores given by laypeople, dentists for female profile

\begin{tabular}{|c|c|c|}
\hline \multirow{2}{*}{ Profile } & \multicolumn{2}{|c|}{ Mean VAS score } \\
\cline { 2 - 3 } & Laypeople & Dentists \\
\hline Profile A & $5.86(3)$ & $3.90(2)$ \\
\hline Profile B & $6.30(7)$ & $4.64(3)$ \\
\hline Profile C & $6.05(5)$ & $5.28(4)$ \\
\hline Profile D & $2.57(1)$ & $2.56(1)$ \\
\hline Profile E & $5.83(2)$ & $5.70(5)$ \\
\hline Profile F & $5.99(4)$ & $7.06(7)$ \\
\hline Profile G & $6.08(6)$ & $6.50(6)$ \\
\hline
\end{tabular}

In parentheses, the final ranking order is shown, with 1 the least attractive and 7 the most attractive. The above table shows comparison of mean VAS scores between laypeople, dentist. The laypeople assigned highest scores for profile B and dentists assigned the highest score for profile $F$ considering as most attractive (Table 4) 

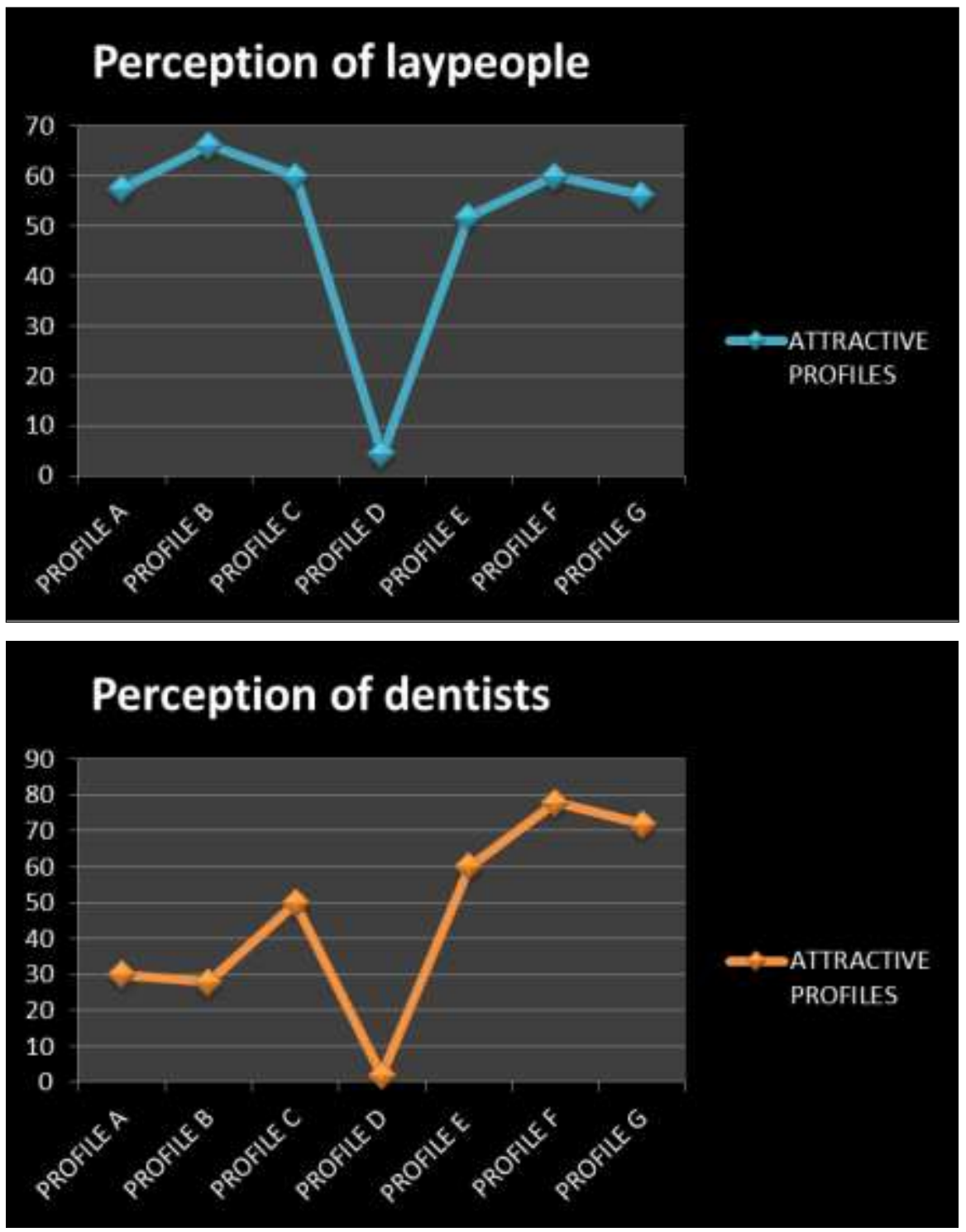

Fig 9: Percentage of attractiveness by laypeople and dentists for female profile

\section{Discussion}

The orthodontist usually prefers the laypeople perception on attractiveness of faces when developing treatment goals for patients with class II division 1 malocclusion. The Bishara and Jakobsen ${ }^{[5]}$ studied the profile changes in patients treated with and without extractions and these were perceived by lay people. The clinicians suggest that four first premolar extractions will cause deteriorated post treatment esthetics by causing dishing in the profile. The Barrer and Ghafar [6] compared the pretreatment and posttreatment profile silhouettes to evaluate the effects of orthodontic treatment on facial profile. Almeidapedrin ${ }^{[7]}$ evaluated the facial profile changes in patients after maxillary premolar extractions. The extraction of premolars is often chosen as alternative for the treatment of patients with Class II division 1 malocclusion in adult individuals with severe overjet where most of the growth has finished ${ }^{[7]}$.

The Doreen ${ }^{[8]}$ evaluated the facial attractiveness of skeletal Class II patients before and after mandibular advancement surgery and perception from people with different backgrounds is evaluated. He found profiles attractive to patients and the layperson may not be coinciding with the orthodontists and surgeons as these clinicians perceive the attractiveness based on their clinical experience and training. The chin imposes esthetic harmony and character to the face, a strong chin or prominent jaw is pleasing in males ${ }^{[8]}$.
The Kaipatur [9] studied the usage of computer software programs in Predicting the results of orthognathic surgery. The Visualized Treatment Objectives are important predictive tools to give a preview of the result for the patients.

The Donatsky ${ }^{[10]}$ studied the immediate postoperative outcome of software planned and predicted changes in hard and soft tissue in a specific individuals using the computerised, cephalometric, orthognathic surgical planning system TIOPS (Total Interactive Orthognathic Planning System) and concluded that the TIOPS planning system helps in simulating orthognathic surgery, planning and best prediction of the outcome ${ }^{[10]}$.

The factors that influence soft tissue position includes the orthodontic treatment, orthognathic surgery and growth of the hard and soft tissues. The nasolabial angle is constructed by two lines passing from the nose and from the upper lip ${ }^{[11]}$. The relation between these two lines is assessed by the angle between the line drawn from columella to the subnasale and line from the subnasale to the mucocutaneous border of the upper lip (columella-labial angle). According to Sinno ${ }^{[4]}$ the average nasolabial angle in females was 104.9 degrees and 97 degrees in males ${ }^{[4]}$.

The evaluation of chin throat region is done in plastic surgery, based on clinical and anthropometric data, and is performed on patients and photographs using soft tissue landmarks. The evaluation of submental region can be done by measuring 
throat length from neck-throat junction (cervical point) to the intersection of the subnasale - soft tissue pogonion and throat line (normal range, $57 \pm 6 \mathrm{~mm}$ ). The position of chin may have an impact on esthetics and profile perception. In patients with short throat length the mandibular setbacks should be avoided; and cases with long throat length are seen in mandibular prognathism and are treated with mandibular setback ${ }^{[12,13]}$.

In this present study the laypeople assigned least score for untreated base image (profile D) and is considered to be least attractive as the profile with greatest Nasolabial angle of 129 degrees (profile A). This indicates that increasing the Nasolabial angle during camouflage therapy does not influence the attractiveness in a positive way. The moderate increase in Nasolabial angle is considered to attractive than the profile with no treatment and better than the increase in Nasolabial angle of 129 degrees (profile A) for both male and female profiles. This indicates that some compensation of a large sagittal interlabial step by increasing the Nasolabial angle is appreciated more than no treatment. The dentists group assigned most of the highest score for profile with increase in chin neck lengths of $51,54,57 \mathrm{~mm}$ respectively (Profile E, F, G). The dentists insisted on the profile with increase in chin neck lengths than increase in Nasolabial angles.

The Burstone mentioned that laypeople perceived the profile balance in terms of upper lip elevation in relation to the nose. The patient with class II division 1 malocclusion will be having acute Nasolabial angle. The Nasolabial angle change is because of $90 \%$ of change in the vermilion border of the lip after retraction of upper incisors and 10 percent was due to increase in the slope of columellar border of nose.

The laypersons are more strongly influenced by factors other than just the profile when looking at photographs of faces in profile than dentists. The dentists react more sensitively to profile lines than do laypersons, and are more negatively influenced by extreme prognathic or retrognathic profile variants ${ }^{[15]}$.

The Kinzinger ${ }^{[14]}$ studied Class II Treatment in Adults by Comparing Camouflage Orthodontics, Dentofacial Orthopedics and Orthognathic Surgery. The major changes in skeletal and soft-tissue occurs during Class II treatment with surgical mandibular advancement rather than camouflage. The camouflage orthodontics with maxillary premolar extractions in adults leads to increase in the nasolabial angle, which is esthetically unacceptable. In this present study both laypeople and dentists assigned highest scores for profiles with chin neck length increase of $54 \mathrm{~mm}$ and $57 \mathrm{~mm}$ for male profile, whereas for female profile laypeople assigned highest scores for nasolabial angles of $113^{\circ}, 121^{\circ}$ and dentists assigned highest scores for profiles with increase in chin neck length of $54 \mathrm{~mm}$ and $57 \mathrm{~mm}$.

\section{Summary and Conclusion}

1. The groups of laypeople, dentists assigned highest rank scores for increase in chin neck length of $57 \mathrm{~mm}$ (profile $\mathrm{G}$ ) and considered as most attractive and least scores for unaltered base image (profile D) for male profile.

2. There is no significant difference between VAS scores for all male profiles between laypeople and dentists.

3. There is significant difference between VAS scores for all female profiles between laypeople and dentists.

4. The laypeople assigned highest score for increase in nasolabial angle $121^{\circ}$ (profile B), dentists assigned highest score for increase in chin neck length of $54 \mathrm{~mm}$ (profile F).

5. As per this study it concludes that laypeople are concerned about the position of lip rather than altered chin positions and dentists preferred the profiles with changes in chin neck lengths.

\section{References}

1. Hambleton RS. The soft-tissue covering of the skeletal face as related to orthodontic problems. Int J Orthod Dent Child. 1964;50:405-20.

2. Burcal RG, Laskin DM, Sperry TP. Recognition of profile change after simulated orthognathic surgery. J Oral Maxillofac Surg. 1987;45:666-70.

3. Lehman JA Jr. Soft-tissue manifestations of aesthetic defects of the jaws: diagnosis and treatment. Clin Plast Surg. 1987; 14:767-83.

4. Sinno HH, Markarian MK, Ibrahim AM, Lin SJ. The ideal nasolabial angle in rhinoplasty: a preference analysis of the general population. Plast Reconstr Surg. 2014;134:201-10.

5. Bishara SE, Jakobsen JR. Profile changes in patients treated with and without extractions: assessments by lay people. Am J Orthod Dentofacial Orthop. 1997;112:63944.

6. James G. Barrer. Silhouette profiles in the assessment of facial esthetics: A comparison of cases treated with various orthodontic appliances. Am J Orthod. 1985,87(5).

7. Almeidapedrin RR, Guinaraes LB, Almeida MR, Almeida RR, Ferreira FP. Assessment of facial profile changes in patients treated with maxillary premolar extractions. Dental Press J Orthod. 2012;17:131-7.

8. Ng Doreen, De Silva RK, Smit R, De Silva H, Farella M. Facial attractiveness of skeletal Class II patients before and after mandibular advancement surgery as perceived by people with different backgrounds. Eur J Orthod 2013;35:515-20.

9. Kaipatur NR, Flores-Mir C. Accuracy of computer programs in predicting orthognathic surgery soft tissue response. J Oral Maxillofac Surg. 2009;67:751-9.

10. Donatsky O, Bjorn-Jorgensen J, Hermund NU, Nielsen $\mathrm{H}$, Holmqvist- Larsen $\mathrm{M}$, Nerder PH. Immediate postoperative outcome of orthognathic surgical planning, and prediction of positional changes in hard and soft tissue, independently of the extent and direction of the surgical corrections required. Br J Oral Maxillofac Surg. 2011;49:386-91.

11. Fitzgerald JP, Nanda RS, Currier GF. An evaluation of the nasolabial angle and the relative inclinations of the nose and upper lip. Am J Orthod Dentofacial Orthop. 1992;102:328-34.

12. Ramzi V. Haddad, Joseph G. Ghafari. Chin-throat anatomy: Normal relations and changes following orthognathic surgery and growth modification. Angle Orthod. 2017;87:696-702.

13. Robert T. Bergman, John Waschak. Longitudinal study of cephalometric soft tissue profile traits between the ages of 6 and 18 years. Angle Orthod. 2014;84:48-55.

14. Kinzinger G, Frye L, Diedrich P. Class II treatment in adults: comparing camouflage orthodontics, dentofacial orthopaedics and orthognathic surgery-a cephalometric study to evaluate various therapeutic effects. J Orofac Orthop. 2008;69:63-91.

15. Honn M, Dietz K, Godt A, Goz G. Perceived relative attractiveness of facial profiles with varying degrees of skeletal anomalies. J Orofac Orthop. 2005;66:187-96 